\title{
Estimation of upward radiances and reflectances at the surface of the sea from above-surface measurements
}

\author{
Ø. Kleiv ${ }^{1}$, A. Folkestad ${ }^{1, \text { a }}$, J. Høkedal ${ }^{2}$, K. Sørensen ${ }^{1}$, and E. Aas ${ }^{3}$ \\ ${ }^{1}$ Norwegian Institute for Water Research, Gaustadalleen 21, 0349 Oslo, Norway \\ ${ }^{2}$ Narvik University College, Lodve Langes gt. 2, 8505 Narvik, Norway \\ ${ }^{3}$ Department of Geosciences, University of Oslo, Gaustadalleen 21, 0349 Oslo, Norway \\ a now at: Rolls-Royce Marine Propulsion, Sjøgata 98, 6065 Ulsteinvik, Norway \\ Correspondence to: E. Aas (eyvind.aas@geo.uio.no)
}

Received: 6 May 2015 - Published in Ocean Sci. Discuss.: 12 June 2015

Revised: 14 August 2015 - Accepted: 12 September 2015 - Published: 2 October 2015

\begin{abstract}
During 4 field days in the years 2009-2011, 22 data sets of measurements were collected in the inner Oslofjord, Norway. The data consist of recordings of spectral nadir radiances in air and water as well as spectral downward irradiance in air. The studied wavelengths are 351, 400, 413, 443, 490, 510, 560, 620, 665, 681, 709 and $754 \mathrm{~nm}$.

The water-leaving radiance and the reflected radiance at the sea surface have been obtained from the measured nadir radiances in air and water, where the latter radiance has been extrapolated upwards to the surface. For comparison we present a simpler and much faster method that determines the water-leaving and reflected radiances solely from abovesurface measurements of upward nadir radiance and downward irradiance. This new method is based on an assumption about similarity in spectral shape of the radiance reflected at the surface, and it makes use of the small ratio between water-leaving and reflected radiances at 351 and $754 \mathrm{~nm}$ in the Oslofjord.

A comparison between the quantities determined by the two mentioned methods shows that the average relative deviations between their results are less than or equal to $15 \%$ for the reflected radiance, at the studied wavelengths. The average relative deviation of the water-leaving radiance at $560 \mathrm{~nm}$ is $24 \%$. These results are obtained for a cloudiness range of 1-8 oktas (12.5-100\%) and solar zenith angles between 37 and $51^{\circ}$. We consider these to be acceptable uncertainties for a first check of satellite products in the inner Oslofjord.
\end{abstract}

\section{Introduction}

The Norwegian Institute for Water Research (NIVA) has been monitoring the coastal waters of Norway by sensors installed onboard ships on fixed and regular routes since 2001, in the FerryBox project and different ESA (European Space Agency) projects (Sørensen et al., 2007). The need for such monitoring rose during the period 1988-2001 when several toxic algal blooms occurred in the Skagerrak and resulted in severe losses for fish farms along the coast (see e.g. Kristiansen and Aas, 2015, and references therein). Monitoring is also an important part of obligations set out in the EU (European Union) Water Framework Directive (2000/60/EC). The recordings of water quality can be coordinated with data from environmental satellites and used for validation purposes. The projects VAMP (Validation of MERIS (MEdium Resolution Imaging Spectrometer) Products), supported by the ESA (European Space Agency), and REVAMP (Regional Validation of MERIS Products), supported by the EU, are examples of such satellite validation projects (Aas et al., 2005; Høkedal et al., 2005; Magnusson et al., 2003; Peters et al., 2005a, b; Sørensen et al., 2003, 2004, 2007). The MERIS L2 products to be validated in the mentioned projects were water-leaving reflectance, algae pigments index 2, total suspended matter, and the sum of yellow-substance absorption and bleached particle absorption.

The advantage of the satellite is that it observes large areas simultaneously, the disadvantage is that the atmosphere influences the recorded radiance and that the estimates of this influence create some uncertainties. Ship-mounted radiance sensors on ships of opportunity avoid the problem of the at- 
mospheric contribution, but they have to be tilted in order to see a part of the sea surface that is not influenced by the ship. The recorded radiance will then be a function of the reflected sky radiance, the reflected direct radiance from the sun, the water-leaving radiance, the nadir angle of the field of view and the azimuth angle relative to the sun, as well as the wind speed. Doxaran et al. (2004) made above-surface recordings of the upward radiance from nadir, $L_{\mathrm{ua}}\left(0^{\circ}\right)$, and at a nadir angle of $40^{\circ}, L_{\mathrm{ua}}\left(40^{\circ}\right)$. The azimuth angle relative to the solar plane was $135^{\circ}$. During clear sky conditions the ratio $L_{\mathrm{ua}}\left(40^{\circ}\right) / L_{\mathrm{ua}}\left(0^{\circ}\right)$ varied in the ranges $0.9-2.2$ and $0.6-2.6$ at 450 and $850 \mathrm{~nm}$, respectively. Under an overcast sky the ranges were 1.0-1.6 at both wavelengths. All of these factors constitute a challenge with regard to a quantitative analysis of the recordings (Bissett et al., 2004; Garaba and Zielinski, 2013; Hooker and Morel, 2003; Mueller et al., 2003; Simis and Olsson, 2013).

As a first step we have simplified the analysis and the problem by reducing the number of nadir angles for the upward radiance to only one, $0^{\circ}$, and we have investigated the possibility of obtaining the spectral distribution of the waterleaving radiance solely from observations in air. The next step will then be to relate these results to recordings by sensors tilted at an angle from the nadir, so that recordings made by radiometric sensors mounted on ships of opportunity can be used directly for improved monitoring of water quality, estimation of water-leaving radiance and validation of satellite products. This step remains to be taken, and it is not described in this paper.

Descriptions of the applied instruments, the data sets of measurements and the environmental conditions are presented in Sect. 2.1. A way of determining the water-leaving radiance as well as the radiance reflected upwards at the surface from recordings of the sub-surface and above-surface upward nadir radiances is outlined in Sect. 2.2, while a simpler method to estimate the reflected and water-leaving radiances from recordings in air is presented in Sect. 2.3. In Sect. 3.1 the constants necessary for the simple method are calculated, and finally the deviation between the two methods is tested in Sect. 3.2.

\section{Material and methods}

\subsection{Field measurements 2009-2011}

The data discussed in this paper were collected during the years 2009-2011, as a part of the ESA supported VAMP II project. Data of the downward spectral irradiance in air, $E_{\mathrm{d}}$, the upward spectral radiance in air from nadir, $L_{\mathrm{ua}}$, and the upward spectral radiance in water from nadir, $L_{\mathrm{uw}}$, will be analysed. These radiometric quantities were recorded by sensors from the TriOS company: $E_{\mathrm{d}}$ by the sensor Ramses AAC-VIS (diameter 4.83 , length $26 \mathrm{~cm}$ ), and $L_{\mathrm{ua}}$ and $L_{\text {uw }}$ by Ramses ARC-VIS (diameter $4.83 \mathrm{~cm}$, length $29.7 \mathrm{~cm}$ plus spray protection cap $2.8 \mathrm{~cm}$ ). Both sensors record by a silicon photodiode array consisting of 256 channels within the range $320-950 \mathrm{~nm}$. The sensors were tested against the FieldCAL device from TriOS at the start of each field cruise. Data were recorded onboard the R/V Trygve Braarud and were stored in a laptop by the MSDA_XE software provided by TriOS. In the post-field processing of the data the wavelengths were restricted to $351 \mathrm{~nm}$ and the OLCI (Ocean and Land Colour Instrument) channels planned for the Sentinel3 satellite (ESA): 400, 413, 443, 490, 510, 560, 620, 665, 681, 709 and $754 \mathrm{~nm}$. Except for 351 and $400 \mathrm{~nm}$ these correspond to the former MERIS wavebands. The Ramses channels closest to the OLCI wavebands were chosen to represent the latter.

The irradiance sensor was mounted on a vertical pole above the roof of the ship bridge of the R/V Trygve Braarud, in order to avoid shading effects. The direction of the normal to the irradiance collector was assumed to be within $0-5^{\circ}$ from the zenith. The radiance sensor was attached to a rig that measured $L_{\mathrm{ua}}$ when the rig was suspended above the sea surface and $L_{\text {uw }}$ when it was submerged in water. The horizontal distance from the rig to the ship side was $3 \mathrm{~m}$. Usually the recording depths in water were $0.5,1,1.5,2,2.5$ and $3 \mathrm{~m}$, corresponding to the well-mixed upper part of the water column. The depths were determined by the length of a wire running over a meter wheel, and at each depth the recording periods $(60 \mathrm{~s})$ were chosen so as to average out the effects of waves. No ship roll was detected. The meter wheel was adjusted to zero when the radiance sensor passed the sea surface. The accuracy of the average depth was then probably better than $5 \mathrm{~cm}$ in most of our cases.

Altogether 22 data sets of $E_{\mathrm{d}}, L_{\mathrm{ua}}$ and $L_{\mathrm{uw}}$ have been analysed. The environmental conditions on the 4 field days are shown in Table 1, and the cloudiness shows that none of the days had a completely clear sky. Based on observations by the Norwegian Meteorological Institute from the last 10 years, the average cloudiness at 12:00 UTC in Oslo during May and June is 5.4 oktas. This means that on 3 of the 4 days in Table 1, the conditions were better than the average.

At each wavelength in each data set the median of the recorded data was applied in order to avoid the influence of spikes and other disturbances. The time series for a recording lasted for $60 \mathrm{~s}$, and during that time around 14-38 spectra could be recorded. In 2009 the average number of spectra was 22. Thus, we could say that the median is based on $26 \pm 12$ values. However, usually the difference between mean and median values was not significant. In 2009 the variation was greatest, as shown by $E_{\mathrm{d}}$ in Table 1 . The variation of $L_{\mathrm{ua}}$ is closely related to $E_{\mathrm{d}}$, and $40 \%$ of the $L_{\mathrm{ua}}$ data had relative deviations between median and mean values less than $0.01,37 \%$ of the data had deviation in the range $0.01-$ $0.05,16 \%$ had deviations in the range $0.05-0.10$, while only $7 \%$ had deviations above 0.10 .

For each data set the ratio $\left(E_{\mathrm{d}}(\max )-E_{\mathrm{d}}(\min )\right) / E_{\mathrm{d}}($ mean $)$ at $560 \mathrm{~nm}$ was calculated, and on each day this ratio had a 
Table 1. Environmental conditions during field work at $59^{\circ} 49^{\prime} \mathrm{N}, 10^{\circ} 34^{\prime} \mathrm{E}$.

\begin{tabular}{lrrrrrr}
\hline Date & $\begin{array}{r}\text { Wind } \\
\text { speed } \\
\left(\mathrm{m} \mathrm{s}^{-1}\right)\end{array}$ & Cloudiness & $\begin{array}{r}\text { Mean } \\
\text { cloudiness } \\
\text { (oktas) }\end{array}$ & $\begin{array}{r}\text { Solar } \\
\text { zenith } \\
\text { angle }\left(^{\circ}\right)\end{array}$ & $\begin{array}{r}\text { Number } \\
\text { of series }\end{array}$ & $\begin{array}{r}\text { Range/mean } \\
\text { of } E_{\mathrm{d}}\end{array}$ \\
\hline 25 June 2009 & 2.8 & $1-3$ & 1.7 & $37-50$ & 9 & $0.01-1.17$ \\
6 May 2010 & 2.5 & $4-8$ & 6.3 & $43-44$ & 3 & $0.09-0.43$ \\
7 May 2010 & 4.9 & $2-3$ & 2.3 & $43-51$ & 7 & $0.01-0.36$ \\
10 May 2011 & 2.3 & $4-6$ & 5.3 & $45-50$ & 3 & $0.02-0.33$ \\
\hline
\end{tabular}

lower and upper value, as displayed by Table 1 . We see that the ratio could vary between 0.01 and 1.17 , meaning a highly variable downward irradiance. Because a median filter had already been used on the recordings, the variation is not a result of sudden shifts but a result of major changes in the irradiance conditions.

The wind speeds, however, were favourable during the 4 field days, being $<5 \mathrm{~m} \mathrm{~s}^{-1}$. In 2011 the sea showed significant patches of pollen, which do not seem to have influenced the recordings.

The recordings were made in yellow-substance-rich coastal waters near the islands of Steilene in the inner Oslofjord. The bio-optical properties of this area have been presented by Aas et al. (2005), Høkedal et al. (2005) and Sørensen et al. (2003, 2004, 2007). While the annual range of the Secchi disk depth at this location stretches from $2 \mathrm{~m}$ during vernal algal bloom to $12 \mathrm{~m}$ under winter conditions (Aas et al., 2014), the Secchi disk depths on the 4 days in Table 1 were in the range of 5.0-6.5 m. The content of yellow substance or CDOM (Coloured Dissolved Organic Material) can be quantified by its absorption coefficient at $442 \mathrm{~nm}$. The mean value \pm the standard deviation of the coefficient at this wavelength, based on data mainly from the Skagerrak and the Oslofjord is $0.62 \pm 0.60 \mathrm{~m}^{-1}$, according to Sørensen et al. (2007).

\subsection{Processing of $L_{\mathrm{uw}}$ measurements}

The radiance from the nadir in water, $L_{\mathrm{uw}}(z)$, is a function of the vertical coordinate $z$, defined positive downwards from the surface. We assume that this function can be approximated by a relationship on the form

$L_{\mathrm{uw}}(z)=L_{\mathrm{uw}}(0) e^{-K z}$

for monochromatic radiance. $K$ is the vertical attenuation coefficient of the radiance (Jerlov, 1976), and it is assumed to be practically constant. Usually the upper $3 \mathrm{~m}$ were well mixed. Due to surface waves it is not possible to measure the radiance value $L_{\mathrm{uw}}(0)$ just beneath the surface with sufficient accuracy, but it can be estimated by linear regression analysis of the expression

$\ln \left(L_{\mathrm{uw}}(z)\right)=\ln \left(L_{\mathrm{uw}}(0)\right)-K z$, where $\ln \left(L_{\mathrm{uw}}(z)\right)$ and $z$ are the variables. Experience confirms that Eq. (2) describes the vertical attenuation of the radiance $L_{\mathrm{uw}}(z)$ fairly well, provided the light conditions in the atmosphere remain constant during the recording. If, on the other hand, the downward irradiance $E_{\mathrm{d}}$ in air varies significantly, we have no perfect method to compensate for this. The best way may be to choose a reference value $E_{\mathrm{d} \text {, ref }}$ for the irradiance among those values observed during the recording of $L_{\mathrm{uw}}(z)$, and then estimate corrected values of $L_{\mathrm{uw}}(z)$ at the different depths by assuming

$\frac{L_{u w, c o r r}}{E_{d, r e f}} \approx \frac{L_{\mathrm{uw}}(z)}{E_{\mathrm{d}}}$

where $E_{\mathrm{d}}$ is the observed irradiance at the time when $L_{\mathrm{uw}}(z)$ was recorded.

The recordings of $L_{\mathrm{uw}}$ should not be made too close to the ship's side. Korsb $\varnothing$ and Aas (1997) investigated the influence of ship-shading on upward radiance onboard the R/V Trygve Braarud in the Oslofjord. The size of the ship is length $22 \mathrm{~m}$, width $7 \mathrm{~m}$, keel depth $3 \mathrm{~m}$ and bridge $6 \mathrm{~m}$ above sea surface. Recordings just behind the stern of the ship, with the sun on the same side, could typically be reduced by up to $20 \%$, while recordings at a distance of $5 \mathrm{~m}$ did not seem to be influenced by the ship. In the present case the distances have been $3 \mathrm{~m}$, on the sunlit side of the ship, and the influence of the ship has been assumed negligible.

While the superstructure of the ship will prevent some of the sky radiance to reach the part of the surface that the radiance sensor is observing, it may also reflect direct solar and diffuse sky radiation towards the same area. This will influence the value of $L_{\mathrm{w}}$. The problem has been discussed by Hooker and Morel (2003) and Hooker and Zibordi (2005). In our case we find that this reflectance was included in the ship-shading effect determined by Korsb $\varnothing$ and Aas (1997).

Another possible source of error is the self-shading effect of downward-looking instruments in the sea. Gordon and Ding (1992) used Monte Carlo simulations to describe this effect, and Zibordi and Ferrari (1995) tested their results by field measurements. Korsbø quantified the self-shading effect in the Oslofjord by in situ measurements (Aas and Korsb $\varnothing$, 1997). The effect was described by

$\ln (1-\varepsilon)=\ln \left(\frac{L_{\mathrm{uw}, \text { meas }}}{L_{\mathrm{uw}, \text { true }}}\right)=-B K r$, 
Table 2. Mean value \pm standard deviation of the vertical attenuation coefficient $K$ of sub-surface radiance from nadir, of the correction factor $f$ for self-shading by the radiance sensor, and of the relative uncertainty $\Delta L_{\mathrm{W}} / L_{\mathrm{W}}$ of the water-leaving radiance at different wavelengths $\lambda$. The number of analysed data sets is 22 .

\begin{tabular}{lccc}
\hline$\lambda(\mathrm{nm})$ & $K\left(\mathrm{~m}^{-1}\right)$ & $f$ & $\Delta L_{\mathrm{W}} / L_{\mathrm{W}}$ \\
\hline 351 & $1.08 \pm 0.17$ & $1.102 \pm 0.017$ & $0.277 \pm 0.139$ \\
400 & $1.01 \pm 0.12$ & $1.095 \pm 0.012$ & $0.077 \pm 0.034$ \\
413 & $0.99 \pm 0.14$ & $1.093 \pm 0.014$ & $0.052 \pm 0.033$ \\
443 & $0.73 \pm 0.10$ & $1.068 \pm 0.010$ & $0.045 \pm 0.034$ \\
490 & $0.45 \pm 0.08$ & $1.042 \pm 0.007$ & $0.039 \pm 0.036$ \\
510 & $0.39 \pm 0.07$ & $1.036 \pm 0.007$ & $0.038 \pm 0.038$ \\
560 & $0.29 \pm 0.05$ & $1.026 \pm 0.005$ & $0.037 \pm 0.046$ \\
620 & $0.44 \pm 0.05$ & $1.041 \pm 0.005$ & $0.042 \pm 0.044$ \\
665 & $0.53 \pm 0.05$ & $1.049 \pm 0.005$ & $0.043 \pm 0.042$ \\
681 & $0.47 \pm 0.05$ & $1.043 \pm 0.005$ & $0.047 \pm 0.046$ \\
709 & $0.69 \pm 0.06$ & $1.064 \pm 0.006$ & $0.063 \pm 0.041$ \\
754 & $0.50 \pm 0.11$ & $1.046 \pm 0.010$ & $0.158 \pm 0.073$ \\
\hline
\end{tabular}

where $\varepsilon$ is the relative error of the measured radiance $L_{\mathrm{uw} \text {, meas }}$, and $L_{\mathrm{uw} \text {, true }}$ is the true radiance. $B$ is a function of wavelength and solar zenith angle, and Korsbø determined its value by correlation analysis between the variables $r$ and $L_{\text {uw,meas. }}$ The radiance sensor has the shape of a cylinder, and $r$ is its radius. $K$ is the vertical attenuation coefficient of the nadir radiance (Jerlov, 1976). From Eq. (4) the correction factor $f(\lambda)=L_{\mathrm{uw}, \text { true }} / L_{\mathrm{uw} \text {, meas }}$ may be written

$f(\lambda)=\frac{L_{\mathrm{uw}, \text { true }}}{L_{\mathrm{uw}, \text { meas }}}=e^{B K r}$.

Based on the solar angles in Table 1 and the results of Aas and Korsbø (1997), we have estimated a mean value of the dimensionless $B$ in Eq. (5) equal to $B=(2.5 \pm 0.6)$ for all wavelengths. Combined with the dimensions of the TriOS radiance sensor described in Sect. 2.1, the corresponding value of the product $B r$ becomes $B r=(0.09 \pm 0.01) \mathrm{m}$. The mean values and standard deviations of $K$ and $f(\lambda)$, based on all 22 data sets of observation for $z$ in the depth range $0.5-3.0 \mathrm{~m}$, are presented in Table 2 at 351 and $400 \mathrm{~nm}$ and the MERIS spectral channels in the range $413-754 \mathrm{~nm}$. It illustrates that if the self-shading effect is not taken into account, the extrapolated value of $L_{\mathrm{uw}}(0)$ found by Eq. (4) will on average be underestimated by 3-9\% in the Oslofjord by the RamsesARC sensor. It should be noted that the small signals produced by the radiance $L_{\mathrm{uw}}(\mathrm{z})$ at the smallest and greatest wavelengths increase the uncertainty of the estimated $K$ and $f(\lambda)$ at these wavelengths.

When $L_{\mathrm{uw} \text {, meas }}(0)$ has been multiplied by the correction factor $f$, resulting in $L_{\mathrm{uw} \text {, true }}(0)$ according to Eq. (5), the transmittance process through the surface has to be considered. This transmittance is first influenced by Fresnel reflection at the surface and then by Snell refraction when the radiance enters the air. The first process reduces the radiance by loss of energy flux, and the second process reduces the radiance by spreading the flux into a greater solid angle. The water-leaving radiance $L_{\mathrm{w}}$ is obtained by multiplying $L_{\mathrm{uw}, \text { true }}(0)$ by the transmittance of nadir radiance through the surface from water to air, $C_{\mathrm{L}}$ :

$L_{\mathrm{w}}=C_{\mathrm{L}} L_{\mathrm{uw}, \text { true }}(0)$.

Because this value for the water-leaving radiance is based on in-water measurements, we will denote it as $L_{\mathrm{w} \text {, meas }}$. By inserting for $L_{\mathrm{uw} \text {, true }}(0)$ from Eq. (5), Eq. (6) may then be written

$L_{\mathrm{w}, \text { meas }}=C_{\mathrm{L}} f(\lambda) L_{\mathrm{uw}, \text { meas }}(0)$.

Austin (1974) assumed a constant refractive index of seawater and obtained the value 0.543 for $C_{\mathrm{L}}$, while Aas et al. (2009) suggested the approximated value 0.546 for the Oslofjord. The factor can also be determined more precisely by a formula taking into account the wavelength $\lambda$, the sea temperature $T$ and the salinity $S$ (Aas et al., 2009). For $T \approx 10^{\circ} \mathrm{C}$ and $S \approx 20$, the formula becomes

$C_{\mathrm{L}} \approx 0.5458+0.00003855(\lambda-550)$,

where $\lambda$ is in nanometres. Our values of $C_{\mathrm{L}}$ were calculated by this formula.

The radiance sensor was also used in air at a height of 1$2 \mathrm{~m}$ above the surface to record the total upward radiance $L_{\mathrm{ua}}$ above the same water mass that produced $L_{\mathrm{w}}$. The radiance meter in air receives light from a greater solid angle than in water and consequently a different calibration, provided by the TriOS company, has to be applied. The calibration factor $F_{\mathrm{w}}$ for the instrument in water, relative to the calibration factor $F_{\mathrm{a}}$ in air, is (e.g. Aas, 1994)

$$
\frac{F_{\mathrm{w}}}{F_{\mathrm{a}}}=\left(\frac{n_{\mathrm{g}}+n_{\mathrm{w}}}{n_{\mathrm{g}}+1}\right)^{2} n_{\mathrm{w}} .
$$

Here $n_{\mathrm{g}}$ and $n_{\mathrm{w}}$ are refractive indices of the glass window of the radiance meter and the seawater, respectively. They are functions of wavelength, and between 351 and $900 \mathrm{~nm}$ the ratio $F_{\mathrm{w}} / F_{\mathrm{a}}$ will vary from 1.774 to 1.722 (Ohde and Siegel, 2003; see also Zibordi and Darecki, 2006).

\subsection{Estimation of reflectance at the surface from $L_{u a}$ and $E_{\mathrm{d}}$}

The total upward nadir radiance $L_{\mathrm{ua}}$ in air consists of two terms; the Fresnel-reflected upward radiance at the surface $L_{\mathrm{r}}$ and the water-leaving radiance $L_{\mathrm{w}}$ :

$L_{\mathrm{ua}}=L_{\mathrm{r}}+L_{\mathrm{w}}$.

When the water-leaving radiance $L_{\mathrm{w}}$ has been determined from Eq. (7), the upward reflected radiance $L_{\mathrm{r}}$ at the surface can be found from Eq. (10). It was mentioned in the former 


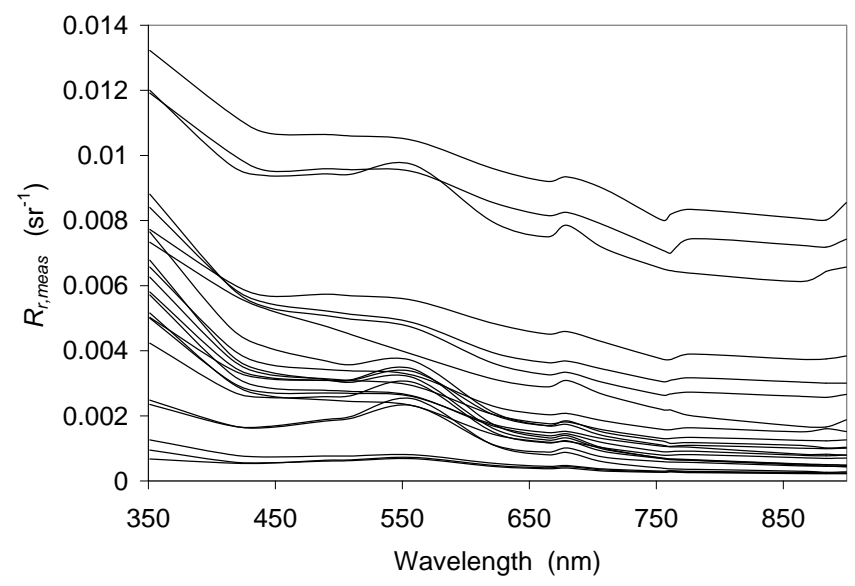

Figure 1. Spectral distribution of the measured radiance reflectance $R_{\mathrm{r}, \text { meas }}$.

section that the superstructure of the ship in general may reflect direct solar and diffuse sky radiation towards the field of view of the radiance sensor and thus influence the values of $L_{\mathrm{r}}$ and $L_{\mathrm{w}}$, but it was also concluded that we think that this effect is negligible in our case.

If there is no wind and the surface is flat, the value of $L_{\mathrm{r}}$ can be estimated from $L_{\mathrm{r}} \approx 0.021 L_{\mathrm{d}}$, where $L_{\mathrm{d}}$ is the sky radiance from zenith and 0.021 is the value of the Fresnel reflectance for normal incidence at the air-water interface. However, if some wind is present, the estimate of $L_{\mathrm{r}}$ from the zenith radiance can lead to significant errors. Aas (2010) found that the contributions from the sun and the diffuse sky to $L_{\mathrm{r}}$ had to be calculated separately, and polynomials for these calculations were presented. Unfortunately, the polynomials require a clear sky, which is not the condition on our field days, as seen by Table 1 . Accordingly, we need a different method to estimate $L_{\mathrm{r}}$.

By dividing Eq. (10) by $E_{\mathrm{d}}$, it can be rewritten as

$R_{\mathrm{ua}}=R_{\mathrm{r}}+R_{\mathrm{w}}$,

where $R_{\mathrm{ua}}(\lambda), R_{\mathrm{r}}(\lambda)$ and $R_{\mathrm{w}}(\lambda)$ represent the spectral radiance reflectances

$R_{\mathrm{ua}}(\lambda)=\frac{L_{\mathrm{ua}}(\lambda)}{E_{\mathrm{da}}(\lambda)}$,

$R_{\mathrm{r}}(\lambda)=\frac{L_{\mathrm{r}}(\lambda)}{E_{\mathrm{da}}(\lambda)}$,

$R_{\mathrm{w}}(\lambda)=\frac{L_{\mathrm{w}}(\lambda)}{\left.E_{\mathrm{da}}\right)}$.

$R_{\mathrm{w}}$ is often termed the remote sensing reflectance, as well as the water-leaving reflectance.

By comparing the spectral distributions of $L_{\mathrm{r}}(\lambda)$ and $R_{\mathrm{r}}(\lambda)$ we have noticed that the spectral shape of $R_{\mathrm{r}}(\lambda)$ is more constant than the shape of $L_{\mathrm{r}}(\lambda)$. Consequently we will base our estimation method on an analysis of $R_{\mathrm{r}}(\lambda)$. Figure 1 presents

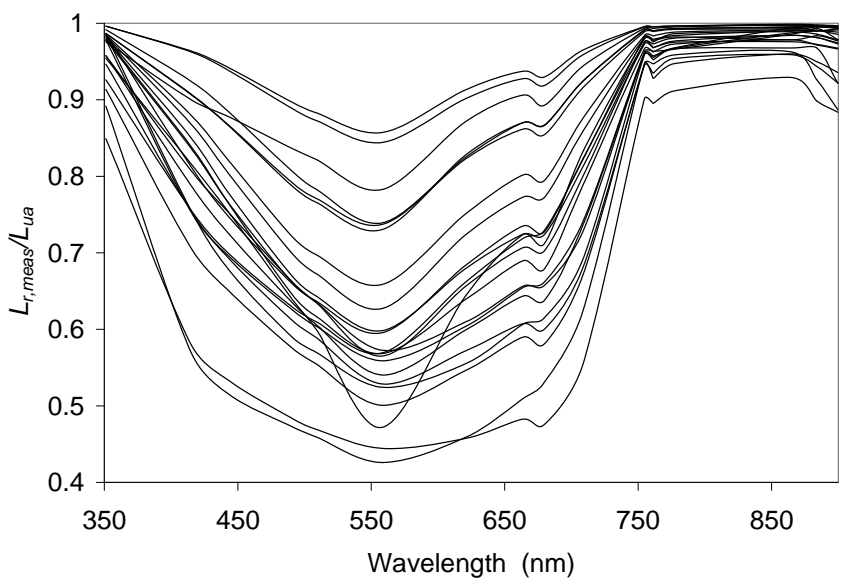

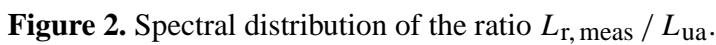

$R_{\mathrm{r}}(\lambda)$ for our data. If we regard $R_{\mathrm{r}}(754)$ as a baseline, and the difference $R_{\mathrm{r}}(351)-R_{\mathrm{r}}(754)$ as a scaling factor, we may be able to describe the spectral shape of $R_{\mathrm{r}}(\lambda)-R_{\mathrm{r}}(754)$ within the interval $351-754 \mathrm{~nm}$ by

$R_{\mathrm{r}}(\lambda)-R_{\mathrm{r}}(754)=A(\lambda)\left[R_{\mathrm{r}}(351)-R_{\mathrm{r}}(754)\right]$,

where $A(\lambda)$ is a constant of proportionality. The value of $A(\lambda)$ can be calculated by determining the best-fit line through the origin for $R_{\mathrm{r}}(\lambda)-R_{\mathrm{r}}(754)$ as a function of $R_{\mathrm{r}}(351)-R_{\mathrm{r}}(754)$, with the spectral curves of Fig. 1 as input. The results will be presented for the MERIS/OLCI wavelengths in Sect. 3.1.

Equation (15) defines $R_{\mathrm{r}}(\lambda)$ as a function of the two variable spectral endpoints $R_{\mathrm{r}}(351)$ and $R_{\mathrm{r}}(754)$ and the shape factor $A(\lambda)$. The reflectances $R_{\mathrm{r}}(351)$ and $R_{\mathrm{r}}(754)$ have been obtained from in-water recordings of $L_{\mathrm{uw}}$ combined with recordings in air of $E_{\mathrm{d}}$, and accordingly we should search for a method to estimate these reflectances solely from our above-surface recordings. If we transform Eq. (10) to

$\frac{L_{\mathrm{r}}}{L_{\mathrm{ua}}}=1-\frac{L_{\mathrm{w}}}{L_{\mathrm{ua}}}$,

this form of the equation gives the useful information that $L_{\mathrm{r}} / L_{\mathrm{ua}}, \approx 1$ at wavelengths where $L_{\mathrm{w}} / L_{\mathrm{ua}} \ll 1$, and we would expect that this was true in the UV and red parts of the spectrum. Ruddick et al. (2006) have pointed out that the spectral shape of $R_{\mathrm{w}}=L_{\mathrm{w}} / E_{\mathrm{d}}$ in the near-infrared part of the spectrum tends to be invariant, because it is dominated by the strong absorption by pure water. This will also influence the spectral shape of $R_{\text {ua }}$. Yellow substance will reduce $R_{\mathrm{w}}$ in the UV. The measured spectral distribution of $L_{\mathrm{r}}(\lambda) / L_{\mathrm{ua}}(\lambda)$ is presented in Fig. 2.

We see that at 351 and $754 \mathrm{~nm}$ the ratio $L_{\mathrm{r}} / L_{\mathrm{ua}}=$ $R_{\mathrm{r}} / R_{\mathrm{ua}}$ comes much closer to 1 than in the central part of the visible spectrum. If we calculate the best-fit line through the origin for $R_{\mathrm{r}}(351)$ as a function of $R_{\mathrm{ua}}(351)$, based on our 


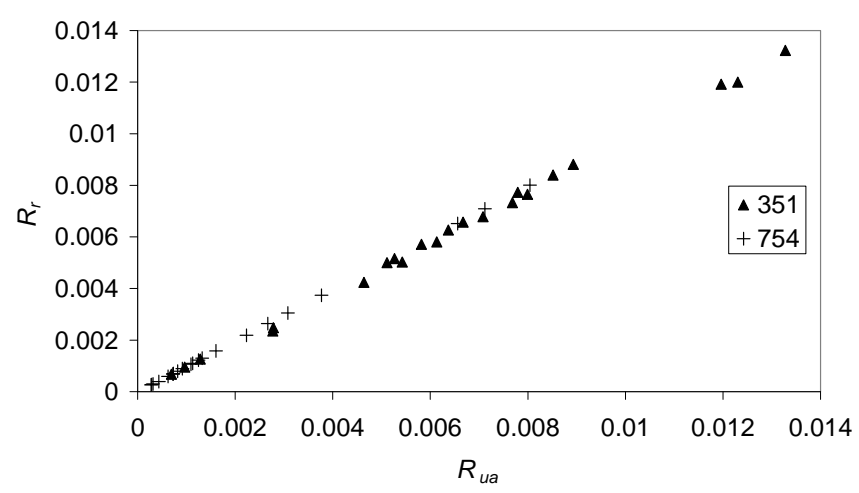

Figure 3. The upward radiance reflectance in air, $R_{\mathrm{r}}$, as a function of the total upward reflectance in air, $R_{\mathrm{ua}}$, at 351 and $754 \mathrm{~nm}$.

recordings, the result may be written

$R_{\mathrm{r}}(351) \approx C(351) R_{\mathrm{ua}}(351)$,

where $C(351)$ is the slope of the line. A similar procedure at $754 \mathrm{~nm}$ gives

$R_{\mathrm{r}}(754) \approx C(754) R_{\text {ua }}(754)$.

Figure 3 presents $R_{\mathrm{r}}$ as a function of $R_{\mathrm{ua}}$ at 351 and $754 \mathrm{~nm}$. Clearly, the deviations from a line through the origin with a slope of 1 are small. By inserting from Eqs. (17) and (18) in Eq. (15), we obtain a relationship for $R_{\mathrm{r}}(\lambda)$ where the only variable input is the value of $R_{\mathrm{ua}}$ at 351 and $754 \mathrm{~nm}$ :

$R_{\mathrm{r}}(\lambda)=A(\lambda) C(351) R_{\mathrm{ua}}(351)+[1-A(\lambda)] C(754) R_{\mathrm{ua}}(754)$.

\subsection{Uncertainties of $L_{\mathrm{ua}}, L_{\mathrm{w}}$ and $L_{\mathrm{r}}$}

In Sect. 2.1 it was pointed out that the relative differences between our applied median and mean values of $L_{\mathrm{ua}}$ in 2009 were less than $5 \%$ for $77 \%$ of the data. In the other years with more stable irradiance conditions the deviations are assumed to have been even less. The calibration of the sensors introduces uncertainties of a similar magnitude. It was mentioned in Sect. 2.1 that the radiance and irradiance sensors were calibrated against the FieldCAL device before each field cruise. According to the TriOS company the applied sensors have an "accuracy better than $6 \%$, depending on spectral range". Based on the magnitude of $L_{\text {ua }}$ in the different parts of the spectrum, and the quality of the field recordings, expressed by the difference between mean and median values, we have estimated that the relative uncertainty of $L_{\mathrm{ua}}$ may be around $3 \%$ in the central parts of the studied spectrum,

Because the water-leaving radiance $L_{\mathrm{w}}$ is obtained from the extrapolated nadir radiance $L_{\mathrm{uw}}(0)$ just beneath the sur-
Table 3. Best-fit values of $A$ in the range $400-709 \mathrm{~nm}$, of $C$ at 351 and $754 \mathrm{~nm}$, and the rms deviations between these values and individual calculations of $A$ and $C$ at the wavelengths $\lambda$.

\begin{tabular}{lcc}
\hline$\lambda(\mathrm{nm})$ & $A$ or $C$ & $\mathrm{rms}$ \\
\hline 351 & 0.977 & 0.039 \\
400 & 0.661 & 0.047 \\
413 & 0.567 & 0.060 \\
443 & 0.470 & 0.078 \\
490 & 0.444 & 0.139 \\
510 & 0.433 & 0.156 \\
560 & 0.429 & 0.248 \\
620 & 0.198 & 0.095 \\
665 & 0.129 & 0.061 \\
681 & 0.147 & 0.079 \\
709 & 0.078 & 0.039 \\
754 & 0.993 & 0.031 \\
\hline
\end{tabular}

face by Eq. (7), the relative uncertainty $\Delta L_{\mathrm{w}} / L_{\mathrm{w}}$ can be approximated by the similar uncertainty $\Delta L_{\mathrm{uw}}(0)$ of the radiance extrapolated to the surface by Eq. (2). If we write Eq. (2) as $y=y_{0}+K z$, where $y=\ln \left(L_{\mathrm{uw}}(z)\right.$ and $y_{0}=\ln \left(L_{\mathrm{uw}}(0)\right)$, then the statistical expression for the standard deviation $s_{y 0}$ of $y_{0}$ is

$s_{y 0}=\frac{K_{\mathrm{L}}}{r}\left(\frac{1-r^{2}}{N-2} \bar{z}^{2}\right)^{0.5}, \quad r=K_{\mathrm{L}} \frac{s_{z}}{s_{y}}$,

where $r$ is the correlation coefficient, $N$ is the number of applied depths, usually 6 , and $s_{y}$ is the standard deviation of $y$. The average values of $s_{y 0} / y_{0}=\Delta L_{\mathrm{w}} / L_{\mathrm{w}}$ are presented in Table 2, and at most of the wavelengths the relative uncertainty is less than $5 \%$. Based on these estimates, we have assumed that the relative uncertainty of the measured $L_{\mathrm{w}}$ may be around $4 \%$ in the central parts of the studied spectrum, and that the uncertainty of the measured $L_{\mathrm{r}}$, depending on $L_{\mathrm{ua}}$ as well as $L_{\mathrm{w}}$, may be around $5 \%$. At the border wavelengths, 351 and $754 \mathrm{~nm}$, the uncertainty of $L_{\mathrm{w}}$ may be greater by a factor of $4-8$, as indicated in Table 2 .

\section{Results}

\subsection{Values of $A$ and $C$}

The spectral values of $A(\lambda)$ in Eq. (15) have been calculated as described in Sect. 2.3, with the spectral curves of Fig. 1 as input. The results are presented for the OLCI wavelengths between 400 and $709 \mathrm{~nm}$ in Table 3. Similarly, the values of $C(351)$ and $C(754)$ were found by determinations of the best-fit lines for Eqs. (17) and (18), and the results are shown in Table 3.

It is possible to calculate individual values of $A$ and $C$ for each series of measurement. The root-mean-square (rms) deviations between these values and the overall best-fit values 


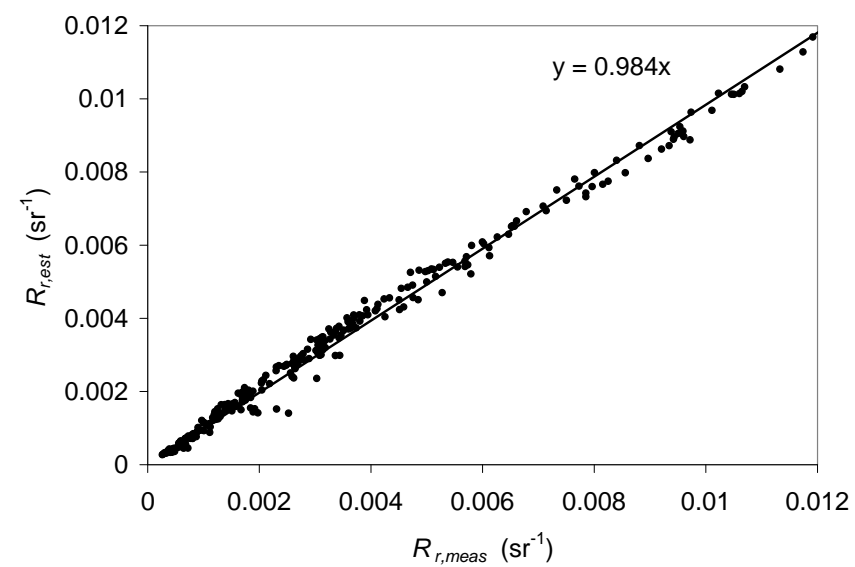

Figure 4. Estimated vs. measured values of the radiance reflectance $R_{\mathrm{r}}$ for all data sets and wavelengths.

of $A$ and $C$ in Table 3 are presented in the last row of Table 3 . At $560 \mathrm{~nm}$ the deviations constitute more than $50 \%$ of the calculated value of $A$. Fortunately, the accuracy of the estimated radiances is far better than the rms values in Table 3 might suggest. This will be demonstrated in the next section.

\subsection{Estimates of $R_{\mathrm{r}}, L_{\mathrm{r}}, R_{\mathrm{w}}$ and $L_{\mathrm{w}}$}

We will denote the estimates of $R_{\mathrm{r}}$ provided by Eqs. (17)(19) as $R_{\mathrm{r} \text {, est }}$. These may then be compared to the values $R_{\mathrm{r} \text {, meas }}$ obtained from the field measurements of $L_{\mathrm{uw}}, L_{\mathrm{ua}}$ and $E_{\mathrm{d}}$. The result is shown in Fig. 4 for the OLCI channels in the range $400-754 \mathrm{~nm}$ with the addition of $351 \mathrm{~nm}$. The best-fit line trough the origin obtains the slope 0.984 , which is close to 1 .

The root-mean-square deviations between $R_{\mathrm{r}, \text { est }}$ and $R_{\mathrm{r} \text {, meas }}$ are presented for the different wavelengths in Table 4 . The rms deviations relative to the mean values are $\leq 13 \%$. We think this is a satisfactory result when the intention is to use the estimates as a first check of satellite products.

If we multiply Eqs. (17)-(19) by $E_{\mathrm{d}}(\lambda)$, we obtain the estimates $L_{\mathrm{r} \text {, est }}(\lambda)$ at the different wavelengths. These results can be compared to the corresponding measured values $L_{\mathrm{r} \text {, meas }}(\lambda)$. Figure 5 presents the estimated vs. the measured reflected radiances. Again, the best-fit line obtains a slope close to 1.007. The relative rms deviations for $L_{\mathrm{r}}$ are only slightly greater than the corresponding deviations for $R_{\mathrm{r}}$, namely $\leq 15 \%$, as demonstrated by Table 4 . At 351 and $754 \mathrm{~nm}$ the deviations between estimated and measured values of $L_{\mathrm{r}}$ are only 3 and $1 \%$, respectively, because at these wavelengths the water-leaving radiance in the Oslofjord becomes so small that the recorded value of $L_{\text {ua }}$ comes close to $L_{\mathrm{r}}$, or $R_{\mathrm{ua}}$ close to $R_{\mathrm{r}}$. An important point here is that the estimate of $L_{\mathrm{r}}$ is not obtained from a measured sky radiance multiplied by a Fresnel type of reflection coefficient, depending on the sea roughness, but from the constants $A$ and $C$ and the measured $L_{\mathrm{ua}}$ and $E_{\mathrm{d}}$. We assume that this method is

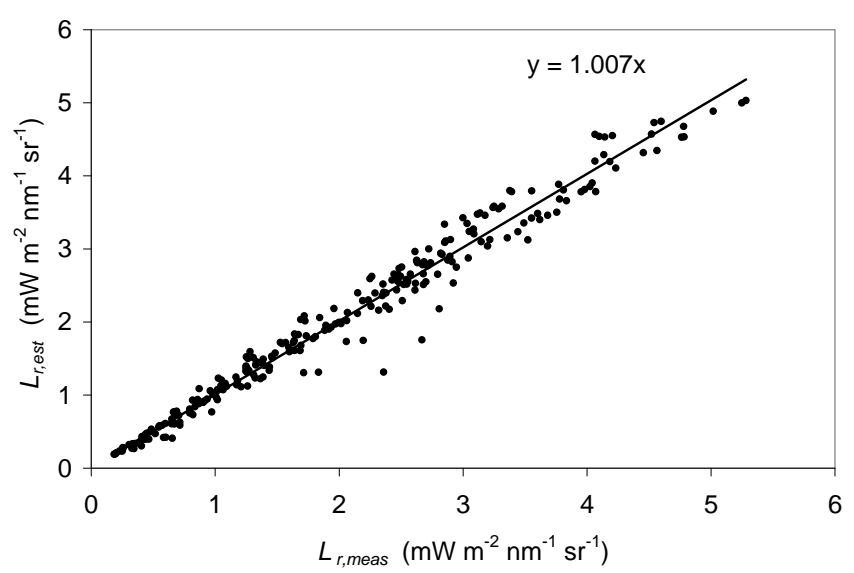

Figure 5. Estimated vs. measured values of the reflected radiance $L_{\mathrm{r}}$ for all data sets and wavelengths.

Table 4. Mean values of measured radiance reflectance $R_{\mathrm{r} \text {, meas }}$ and reflected radiance $L_{\mathrm{r}}$, meas, and the rms deviations between these quantities and the corresponding estimated values.

\begin{tabular}{|c|c|c|c|c|c|c|}
\hline \multirow{2}{*}{$\begin{array}{l}\lambda \\
(\mathrm{nm})\end{array}$} & \multicolumn{3}{|c|}{$R_{\mathrm{r}, \text { meas }}$} & \multicolumn{3}{|c|}{$L_{\mathrm{r} \text {, meas }}$} \\
\hline & $\begin{array}{l}\text { mean } \\
\left(10^{-5} \mathrm{~s}\right.\end{array}$ & $\begin{array}{l}\mathrm{rms} \\
\left.\mathrm{sr}^{-1}\right)\end{array}$ & $\begin{array}{l}\frac{\mathrm{rms}}{\text { mean }} \\
(\%)\end{array}$ & $\begin{array}{l}\text { mean } \\
\left(10^{-2} \mathrm{~mW} \mathrm{~m}^{-2}\right.\end{array}$ & $\begin{array}{c}\mathrm{rms} \\
\left.-2 \mathrm{~nm}^{-1} \mathrm{sr}^{-1}\right)\end{array}$ & $\begin{array}{l}\frac{\mathrm{rms}}{\text { mean }} \\
(\%)\end{array}$ \\
\hline 351 & 615 & 17 & 2 & 157 & 4.5 & 3 \\
\hline 400 & 477 & 21 & 4 & 229 & 10 & 4 \\
\hline 413 & 438 & 25 & 6 & 249 & 13 & 5 \\
\hline 443 & 400 & 23 & 6 & 264 & 16 & 6 \\
\hline 490 & 393 & 29 & 7 & 276 & 24 & 9 \\
\hline 510 & 389 & 32 & 8 & 277 & 27 & 10 \\
\hline 560 & 391 & 50 & 13 & 274 & 42 & 15 \\
\hline 620 & 289 & 27 & 9 & 172 & 18 & 10 \\
\hline 665 & 260 & 22 & 9 & 144 & 14 & 9 \\
\hline 681 & 268 & 27 & 10 & 144 & 16 & 11 \\
\hline 709 & 237 & 20 & 8 & 117 & 11 & 9 \\
\hline 754 & 205 & 2.1 & 1 & 88 & 1.3 & 1 \\
\hline
\end{tabular}

valid for solar zenith angles in the range $37-50^{\circ}$ and wind speeds up to $5 \mathrm{~m} \mathrm{~s}^{-1}$ in the Oslofjord.

According to Eq. (11) we will obtain the estimate $R_{\mathrm{w}, \text { est }}(\lambda)$ by subtracting $R_{\mathrm{r} \text {, est }}(\lambda)$ from $R_{\mathrm{ua}}(\lambda)$. The estimates of this quantity at 351 and $754 \mathrm{~nm}$ can be obtained by combining Eqs. (11) and (17)-(18) with the results of Table 3. The results are

$R_{\mathrm{w}, \text { est }}(351)=(1-0.977) R_{\mathrm{ua}}(351)=0.023 R_{\mathrm{ua}}(351)$,

and

$R_{\mathrm{w}, \text { est }}(754)=(1-0.993) R_{\mathrm{ua}}(754)=0.007 R_{\mathrm{ua}}(754)$.

The estimated vs. the measured values of $R_{\mathrm{W}}$ at $351 \mathrm{~nm}$ and the MERIS/OLCI channels from 400 to $754 \mathrm{~nm}$ are shown in Fig. 6. The best-fit line once more obtains a slope close to 1 , namely 1.028 , but the deviations from the line seem to be greater than in Fig. 5. This, however, is not true. In fact, the rms deviations are exactly the same for $R_{\mathrm{w}, \text { est }}(\lambda)$ as for 


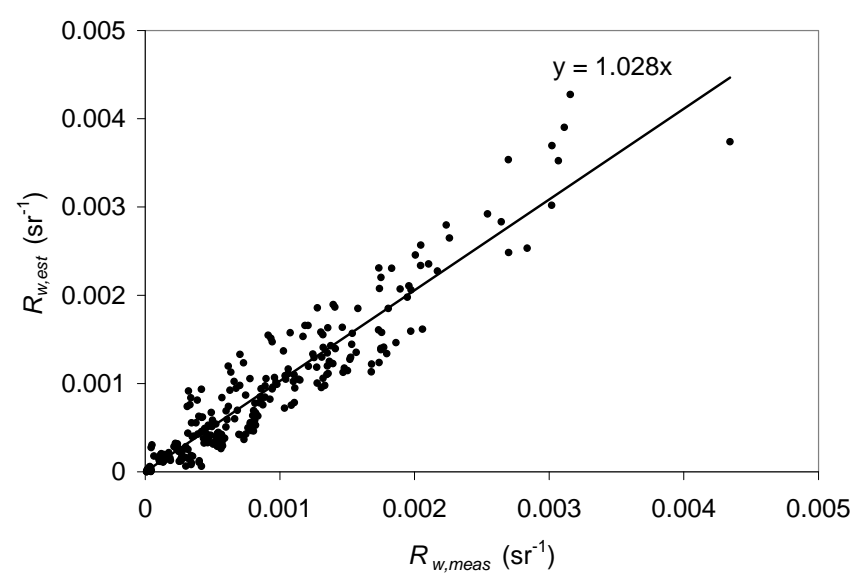

Figure 6. Estimated vs. measured values of the remote sensing reflectance $R_{\mathrm{W}}$ for all data sets and wavelengths.

Table 5. Mean values of measured remote sensing reflectance $R_{\mathrm{W} \text {, meas }}$ and water-leaving radiance $L_{\mathrm{W}}$, meas, and the rms deviations between these quantities and the corresponding estimated values.

\begin{tabular}{|c|c|c|c|c|c|c|}
\hline \multirow{2}{*}{$\begin{array}{l}\lambda \\
(\mathrm{nm})\end{array}$} & \multicolumn{3}{|c|}{$R_{\mathrm{W}, \text { meas }}$} & \multicolumn{3}{|c|}{$L_{\mathrm{W}, \text { meas }}$} \\
\hline & $\begin{array}{l}\text { mean } \\
\left(10^{-}\right.\end{array}$ & $\left.\mathrm{r}^{-1}\right)$ & $\begin{array}{l}\frac{\mathrm{rms}}{\text { mean }} \\
(\%)\end{array}$ & $\begin{array}{l}\text { mean } \\
\left(10^{-2}\right.\end{array}$ & $\begin{array}{l}\mathrm{rms} \\
\left.{ }^{2} \mathrm{~nm}^{-1} \mathrm{sr}^{-1}\right)\end{array}$ & $\begin{array}{l}\frac{\mathrm{rms}}{\text { mean }} \\
(\%)\end{array}$ \\
\hline 351 & 19 & 17 & 89 & 5.2 & 4.5 & 87 \\
\hline 400 & 71 & 21 & 29 & 39 & 10 & 25 \\
\hline 413 & 74 & 25 & 33 & 48 & 13 & 28 \\
\hline 443 & 97 & 23 & 24 & 74 & 16 & 21 \\
\hline 490 & 146 & 29 & 20 & 120 & 24 & 20 \\
\hline 510 & 164 & 32 & 19 & 137 & 27 & 20 \\
\hline 560 & 213 & 50 & 24 & 173 & 42 & 24 \\
\hline 620 & 95 & 27 & 28 & 71 & 18 & 25 \\
\hline 665 & 62 & 22 & 36 & 45 & 14 & 30 \\
\hline 681 & 67 & 27 & 40 & 46 & 16 & 35 \\
\hline 709 & 32 & 20 & 63 & 21 & 11 & 52 \\
\hline 754 & 2.9 & 2.1 & 72 & 1.6 & 1.3 & 80 \\
\hline
\end{tabular}

$R_{\mathrm{r} \text {, est }}(\lambda)$, because Eq. (11) links the two quantities together, and $R_{\mathrm{ua}}$ is the same for both the estimated quantities. In Tables 4 and 5 the rms values are equal for $R_{\mathrm{r}}$ and $R_{\mathrm{W}}$, but the ratio between the rms and the mean value becomes greater for $R_{\mathrm{W}}$ than for $R_{\mathrm{r}}$, because the mean values of $R_{\mathrm{w}}$ are much smaller than the corresponding values of $R_{\mathrm{r}}$.

If we multiply the estimates $R_{\mathrm{w} \text {, est }}(\lambda)$ by $E_{\mathrm{d}}(\lambda)$, we obtain the estimates $L_{\mathrm{w}, \text { est }}(\lambda)$, which again can be compared to the measured $L_{\mathrm{w} \text {, meas }}(\lambda)$. Figure 7 presents the estimated vs. the measured water-leaving radiances, and the best-fit line has the slope 0.995 . At $560 \mathrm{~nm}$, where the water-leaving radiance has its peak value, the relative rms deviation is $24 \%$ (Table 5), which we think is a surprisingly low value, considering the uncertainties involved. We also consider this rms deviation to be a realistic example of what can be achieved in our waters. Hooker and Zibordi (2005) refer to an accuracy of $5 \%$ required by NASA (National Aeronautics and Space

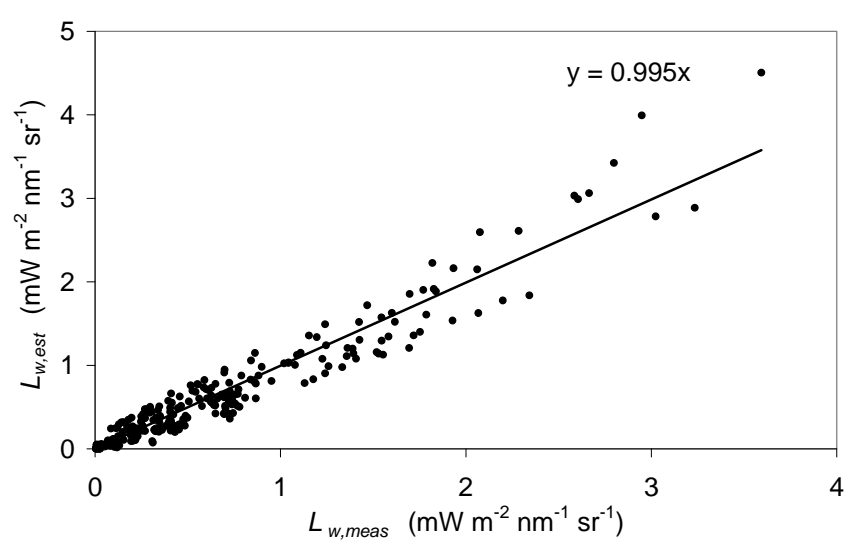

Figure 7. Estimated vs. measured values of the water-leaving radiance $L_{\mathrm{W}}$ for all data sets and wavelengths.

Table 6. Values of $A$ and $C$ and the measured radiance reflectance $R_{\mathrm{r} \text {, meas }}$ at $560 \mathrm{~nm}$ for all data sets taken together and for the test case with $A$ and $C$ determined from 9 data sets and applied on the remaining 13 data sets. The rms represents the deviations between $R_{\mathrm{r} \text {, meas }}$ and the corresponding estimated values of $R_{\mathrm{r}}$, est.

\begin{tabular}{lcccccc}
\hline $\begin{array}{l}\text { Number } \\
\text { of data sets }\end{array}$ & $C(351)$ & $A(560)$ & $C(754)$ & \multicolumn{3}{c}{$R_{\mathrm{r}, \text { meas }}(560)$} \\
mean & & & $\left.\begin{array}{r}\text { rms } \\
\left(10^{-5}\right.\end{array} \mathrm{sr}^{-1}\right)$ & $\begin{array}{r}\frac{\text { rms }}{\text { mean }} \\
(\%)\end{array}$ \\
\hline 22 & 0.977 & 0.429 & 0.993 & 391 & 50 & 13 \\
\hline 9 selected & 0.955 & 0.488 & 0.990 & 390 & 63 & 16 \\
13 extra & & & & 392 & 48 & 12 \\
\hline
\end{tabular}

Administration) for ground truth measurements, but this we think can only be achieved under very favourable conditions.

It could be argued that because we have calculated the deviations by the same data set that was applied for the best-fit constants, the test on an independent data set might produce greater deviations. Accordingly, we have tried to make such tests by dividing our data sets into two parts: one for the determination of the constants $A$ and $C$, and one for the calculation of deviations between measured and estimated reflectances. As an example, the 9 sets from 2009 have been selected for the determination of $A$ and $C$, and then these values have been applied to the remaining 13 sets from 2010 to 2011. The results for the radiance reflectance $R_{\mathrm{r}}$ at $560 \mathrm{~nm}$ are presented in Table 6 . We find that the results for all sets together or for the sets divided into two parts are not significantly different.

\section{Summary and conclusions}

We have analysed 22 sets of measurement from four field days in the years 2009-2011, collected onboard the R/V Trygve Braarud in the inner Oslofjord. The data consist of recordings of the sub-surface nadir radiance $L_{\mathrm{uw}}$, the cor- 
responding upward radiance $L_{\mathrm{ua}}$ in air, and the downward irradiance $E_{\mathrm{d}}$ in air. Comments on the data, the applied sensors and the environmental conditions have been presented in Sect. 2.1.

Section 2.2 describes how the water-leaving radiance $L_{\mathrm{w}}$ and the reflected radiance $L_{\mathrm{r}}$ at the sea surface are determined from $L_{\mathrm{ua}}$ and $L_{\mathrm{uw}}$. A simpler and much faster method, which determines the reflectance $R_{\mathrm{r}}=L_{\mathrm{r}} / E_{\mathrm{d}}$ as well as $L_{\mathrm{r}}$ and $L_{\mathrm{w}}$ solely from the measurements in air of $L_{\mathrm{ua}}$ and $E_{\mathrm{d}}$, is presented in Sect. 2.3. The coefficients $A$ and $C$, defined by Eqs. (15) and (17)-(18), are key parts of this method, and they are quantified in Sect. 3.1. The applied wavelengths are $351 \mathrm{~nm}$ in addition to the 11 OLCI channels in the range 400 $754 \mathrm{~nm}$.

A comparison between the quantities determined by the two methods shows that the average relative deviations between their results are less than or equal to 13 and $15 \%$ for $R_{\mathrm{r}}$ and $L_{\mathrm{r}}$, respectively (Sect. 3.2). The deviations of the water-leaving radiance $L_{\mathrm{w}}$ and the corresponding reflectance $R_{\mathrm{w}}=L_{\mathrm{w}} / E_{\mathrm{d}}$ are identical to those of $R_{\mathrm{r}}$ and $L_{\mathrm{r}}$ when measured in absolute units, but in relative units they become greater because $R_{\mathrm{w}}$ and $L_{\mathrm{w}}$ are smaller than $R_{\mathrm{r}}$ and $L_{\mathrm{r}}$. On the other hand, at $560 \mathrm{~nm}$ where $L_{\mathrm{w}}$ obtains its maximum values, the average relative deviation between the two methods is still only $24 \%$ for both $R_{\mathrm{w}}$ and $L_{\mathrm{w}}$, and we consider this to be an acceptable uncertainty of the estimates. These results have been obtained for a cloudiness range of 1-8 oktas and solar zenith angles between 37 and $51^{\circ}$.

Our overall conclusion is that the suggested method to estimate reflected and water-leaving radiances, based on measurements in air of upward nadir spectral radiance and downward spectral irradiance, provides results with a satisfactory accuracy. The remaining task is to determine the relationships between radiance from nadir and radiance recorded by tilted sensors. The recordings made by radiometric sensors mounted on ships of opportunity can then be used for a first check of the remote sensing reflectance estimated by satellites, at significantly lower costs than those required by the use of research vessels.

Author contributions. All authors participated in parts of the field work. Post-field processing of the data was made by Folkestad and Kleiv. Sørensen directed the project. Aas prepared the manuscript with comments and data from the co-authors.

Acknowledgements. The field work and the first processing of the data was part of the PRODEX project C90383 Validation of MERIS products - VAMP II, supported by ESA. A minor part of the data processing was supported by the Department of Geosciences at the University of Oslo.

Edited by: O. Zielinski

\section{References}

Aas, E.: A simple method for radiance calibration, in: European workshop on optical ground truth instrumentation for the validation of space-borne optical remote sensing data of the marine environment 23-25 November 1993, Netherlands Institute for Sea Research, Rep. 1994-3, 39-44, 1994.

Aas, E.: Estimates of radiance reflected towards the zenith at the surface of the sea, Ocean Sci., 6, 861-876, doi:10.5194/os-6861-2010, 2010

Aas, E. and Korsbø, B.: Self-shading effect by radiance meters on upward radiance observed in coastal waters, Limnol. Oceanogr., 42, 968-974, 1997.

Aas, E., Høkedal, J., and Sørensen, K.: Spectral backscattering coefficient in coastal waters, Int. J. Remote Sens., 26, 331-343, 2005.

Aas, E., Høkedal, J., and Højerslev, N. K.: Conversion of subsurface reflectances to above-surface MERIS reflectance, Int. J. Remote Sens., 30, 5767-5791, 2009.

Aas, E., Høkedal, J., and Sørensen, K.: Secchi depth in the Oslofjord-Skagerrak area: theory, experiments and relationships to other quantities, Ocean Sci., 10, 177-199, doi:10.5194/os-10177-2014, 2014.

Austin, R. W.: The remote sensing of spectral radiance from below the ocean surface, edited by: Jerlov,N. G. and Steeman Nielsen, E., Optical Aspects of Oceanography, Academic Press, London, 317-344, 1974.

Bissett, W. P., Arnone, R. A., Davis, C. O., Dickey, T. D., Dye, D., Kohler, D. D. R., and Gould, J., R. W.: From meters to kilometers: A look at ocean-color scales of variability, spatial coherence, and the need for fine-scale remote sensing in coastal ocean optics, Oceanography, 17, 32-43, 2004.

Doxaran, D., Nagur Cherukuru, R. C., and Lavender, S. J.: Estimation of surface reflection effects on upwelling radiance field measurements in turbid waters, J. Opt. A, 6, 690-697, 2004.

Garaba, S. P. and Zielinski, O.: Methods in reducing surface reflected glint for shipborne above-water remote sensing, J. Europ. Opt. Soc.-Rap. Publ., 8, 13058, 8 pp., doi:10.2971/jeos.2013.13058, 2013.

Gordon, H. R. and Ding, K.: Self-shading of in-water optical instruments, Limnol. Oceanogr., 37, 491-500, 1992.

Hooker, S. B. and Morel, A.: Platform and environmental effects on above-water determinations of water-leaving radiances, J. Atmos. Oceanic Techn., 20, 187-205, 2003.

Hooker, S. B. and Zibordi, G.: Platform perturbations in abovewater radiometry, Appl. Opt., 44, 553-567, 2005.

Høkedal, J., Aas, E., and Sørensen, K.: Spectral optical and biooptical relationships in the Oslo Fjord compared with similar results from the Baltic Sea, Int. J. Remote Sens., 26, 371-386, 2005.

Jerlov, N. G.: Marine Optics, Elsevier, Amsterdam, 1976.

Korsbø, B. and Aas, E.: Ship-shading effects on upward radiance and irradiance in coastal waters, Rep. Dept. Geophys., Univ. Oslo, 101, 13 pp., 1997.

Kristiansen, T. and Aas, E.: Water type quantification in the Skagerrak, the Kattegat and off the Jutland west coast, Oceanologia, 57, 177-195, 2015.

Magnusson, J., Dahl, E., Karud, J., Sørensen, K., Willbergh, M., and Aas, E.: Validation of methods for monitoring of coastal and open sea areas with satellites and sensors on ships of opportunity, NIVA Report SNO 4710-2003, 37 pp., 2003. 
Mueller, J. L., Davis, C., Arnone, R., Frouin, R., Carder, K., Lee, Z. P., Steward, R. G., Hooker, S., Mobley, C. D., and McLean, S.: Above-water radiance and remote sensing reflectance measurement and analysis protocols, in: Ocean Optics Protocols For Satellite Ocean Color Sensor Validation, Revision 4, Volume III: Radiometric Measurements and Data Analysis Protocols, NASA/TM-2003-21621/Rev-Vol. III, 21-31, 2003.

Ohde, T. and Siegel, H.: Derivation of immersion factors for the hyperspectral TriOS radiance sensor, J. Opt. A, 5, L12-L14, 2003.

Peters, S. W. M., Eleveld, M., Pasterkamp, R., van der Woerd, H., Devolder, M., Jans, S., Park, Y., Ruddick, K., Block, T., Brockmann, C., Doerffer, R., Kraseman, H., Röttgers, R., Schönfeld, W., Jørgensen, P. V., Tilstone, G., Martinez-Vincente, V., Moore, G., Sørensen, K., Høkedal, J., Johnsen, T. M., Lømsland, E. R., and Aas, E.: Atlas of Chlorophyll-a concentration for the North Sea based on MERIS imagery of 2003, Vrije Universiteit, Amsterdam, 121 pp., 2005a.

Peters, S., Brockmann, C., Eleveld, M. , Pasterkamp, R., van der Woerd, H., Ruddick, K., Park, Y., Block, T., Doerffer, R., Krasemann, H., Roettgers, R., Schoenfeld, W., Joergensen, P., Tilstone, G., Martinez-Vicente, V., Moore, G., Soerensen, K., Hokedal, J., and Aas, E.: Regional chlorophyll retrieval algorithms for North Sea waters: intercomparison and validation. Proceedings of the MERIS (A)ATSR Workshop 2005 (ESA SP-597), 2630 September 2005 ESRIN, Frascati, Italy, edited by: Lacoste, H.. Published on CDROM, p. 19.1 Publication Date: 12/2005, $2005 b$.
Ruddick, K. G., De Cauwer, V., Park, Y., and Moore, G.: Seaborne measurements of near infrared water-leaving reflectance: The similarity spectrum for turbid waters, Limnol. Oceanogr., 51, 1167-1179, 2006.

Simis, S. G. H. and Olsson, J.: Unattended processing of shipborne hyperspectral reflectance measurements, Rem. Sens. Environ., 135, 202-212, 2013.

Sørensen, K., Høkedal, J., Aas, E., Doerffer, R., and Dahl, E.: Early results for validation of MERIS water products in the Skagerrak. Proceedings of "Envisat Validation Workshop", 9-13 December 2002, Frascati, Italy (ESA SP-531, March 2003), 2003.

Sørensen, K., Aas, E., Høkedal, J., Severinsen, G., Doerffer, R., and Dahl, E.: Validation of MERIS water products in the Skagerrak. MAVT Workshop. Proceedings of Envisat Validation Workshop, 20-24 October 2003, Frascati, Italy (ESA CD-ROM), 2004.

Sørensen, K., Aas, E., and Høkedal, J.: Validation of MERIS water products and bio-optical relationships in the Skagerrak, Int. J. Remote Sens., 28, 555-568, 2007.

Zibordi, G. and Darecki, M.: Immersion factors for the RAMSES series of hyper-spectral underwater radiometers, J. Opt. A, 8, 252, doi:10.1088/1464-4258/8/3/005, 2006.

Zibordi, G. and Ferrari, G. M.: Instrument self-shading in underwater optical measurements: experimental data, Appl. Opt., 34, 2750-2754, 1995. 